\title{
Designing Effective Habitat Studies: Quantifying Multiple Sources of Variability in Bat Activity
}

Author(s): Joern Fischer, Jenny Stott, Bradley S. Law, Maria D. Adams, and Robert I. Forrester Source: Acta Chiropterologica, 11(1):127-137.

Published By: Museum and Institute of Zoology, Polish Academy of Sciences

DOI: http://dx.doi.org/10.3161/150811009X465749

URL: http://www.bioone.org/doi/full/10.3161/150811009X465749

BioOne (www.bioone.org) is a nonprofit, online aggregation of core research in the biological, ecological, and environmental sciences. BioOne provides a sustainable online platform for over 170 journals and books published by nonprofit societies, associations, museums, institutions, and presses.

Your use of this PDF, the BioOne Web site, and all posted and associated content indicates your acceptance of BioOne's Terms of Use, available at www.bioone.org/page/terms_of_use.

Usage of BioOne content is strictly limited to personal, educational, and non-commercial use. Commercial inquiries or rights and permissions requests should be directed to the individual publisher as copyright holder. 


\title{
Designing effective habitat studies: quantifying multiple sources of variability in bat activity
}

\author{
Joern Fischer ${ }^{1,4}$, Jenny StotT $^{1}$, Bradley S. LaW $^{2}$, Maria D. AdAmS ${ }^{2}$, and Robert I. Forrester ${ }^{3}$ \\ ${ }^{1}$ The Fenner School of Environment and Society, The Australian National University, Canberra ACT 0200, Australia \\ ${ }^{2}$ Forest Science Centre, Department of Primary Industries, PO Box 100, Beecroft NSW 2119, Australia \\ ${ }^{3}$ Statistical Consulting Unit, The Australian National University, Canberra ACT 0200, Australia \\ ${ }^{4}$ Corresponding author: E-mail: joern.fischer@anu.edu.au
}

\begin{abstract}
Common aims of habitat studies are to differentiate between (i) suitable and unsuitable sites for a given species, and (ii) sites used by different communities of species. To quantify differences between sites, field data of site use must be precise enough that true underlying between-site variability is not masked by within-site measurement error. We designed a pilot study to guide the development of a survey protocol for a habitat study on bats in an agricultural landscape in southeastern Australia. Three woodland sites and two scattered tree sites of 2 ha each were surveyed for nine consecutive nights. At three locations within each site (spaced $>50 \mathrm{~m}$ apart) one or two Anabat detectors were mounted $1 \mathrm{~m}$ above ground or in a tree ( $2 \mathrm{~m}$ above ground). We used mixed regression models to quantify multiple sources of variability in bat calling activity, and graphical data analysis to visualise how increases in survey effort were likely to affect inference. For the five most active species, we found that typically over $40 \%$ of variability in nightly detections occurred at the between-site level; approximately $10 \%$ occurred between locations within sites; approximately $20 \%$ was explained by night-to-night differences; and approximately $30 \%$ of variability was not attributable to systematic variation within experimental units. Differences in community composition between sites were clearly evident when two or more detectors per site were used for four or more nights. We conclude with six general considerations for the design of effective habitat studies. These are to (i) consider key contrasts of interest; (ii) use data from mild, calm, dry nights only; (iii) calibrate detectors; (iv) use multiple detectors where possible, or move a single detector within a site; (v) survey for multiple nights; and (vi) where vertical differentiation in habitat use is likely, mount detectors at different heights. These considerations need to be balanced within the context of financial and logistical constraints.
\end{abstract}

Key words: Anabat detectors, survey effort, southeastern Australia, scattered trees, paddock trees, woodlands, bats

\section{INTRODUCTION}

The quantification of habitat associations for different taxa is a common goal in ecology, and can be useful to inform land management decisions (Guisan and Zimmermann, 2000). A vital first step in the development of robust habitat models is the collection of appropriate field data (Austin, 2002). Invariably, ecologists face a trade-off between collecting highly precise data from relatively few locations, or collecting less precise data from a larger number of locations. This trade-off may be resolved in part by an understanding of different sources of variability in field data, and how substantial withinsite variability is relative to between-site variability. If temporal and spatial within-site variability are negligible, between-site differences can be quantified accurately with relatively little survey effort per site. In contrast, if temporal or spatial within-site variability is large, significant differences between sites may be masked by excessively imprecise sitelevel data, even if the total number of sites is large.

Several bat ecologists have attempted to quantify how changes in survey methodology can lead to increasingly precise estimates of bat activity (Hayes, 1997; Moreno and Halffter, 2000; Duchamp et al., 2006). Although we appreciate the value of using multiple survey techniques in combination (O'Farrell and Gannon, 1999; Duffy et al., 2000; Milne et $a l ., 2005)$, in this paper we are concerned with studies that rely solely on the use of ultrasound bat detectors. In contrast to trapping studies, acoustic monitoring is often the only logistically feasible way of obtaining bat data over a large study area. For acoustic monitoring, key sources of variability in measured bat activity include: (i) Differences in 
detectability of bat species. Different species' calls vary in intensity (Fenton and Bell, 1981), and different detection systems vary in their ability to detect different ultrasonic frequencies (Waters and Walsh, 2002). In addition, some species tend to fly higher than others, which may affect their probability of detection (Griffin, 1971; O'Neill and Taylor, 1986; Hayes and Gruver, 2000). Between-species differences in activity levels therefore cannot be readily deduced from acoustic monitoring (Hayes, 2000);

(ii) Night-to-night variability in bat activity. To reduce variability from this source, it is often desirable to survey bats for multiple nights (Hayes, 1997; Moreno and Halffter, 2000; Broders, 2003; Milne et al., 2005). However, increasing the number of nights may increase the likelihood of surveying in nights with sub-optimal conditions, suggesting that more nights will not always lead to more precise estimates of bat activity;

(iii) Differences between multiple bat detectors in their ability to detect calls. To reduce variability from this source, Larson and Hayes (2000) outlined a protocol to calibrate (Anabat) detectors. Despite careful calibration, differently placed detectors may record different levels of activity, and are likely to miss some of the activity actually present at a site (Law et al., 1998; Weller and Zabel, 2002; Milne et al., 2004; Duchamp et al., 2006);

(iv) Horizontal heterogeneity in bat activity within a site. Especially if sites are large or variable in vegetation structure, some bat species may preferentially use certain parts of a site over others (Hayes, 2000). To reduce variability from this source, detectors may be moved every night within the site (Lumsden and Bennett, 2005), or multiple detectors may be used simultaneously (Law, 2004; Duchamp et al., 2006). Variation in vegetation structure can also influence call detectability (Patriquin et al., 2003), but careful placement of detectors in vegetation gaps can minimize these effects (Patriquin et al., 2003);

(v) Vertical heterogeneity in bat activity at a site (Hayes and Gruver, 2000; Menzel et al., 2005). For example, fast-flying species may fly higher to avoid structural clutter (O'Neill and Taylor, 1986), whereas slow-flying species may preferentially hover or glean around dense vegetation (O'Neill and Taylor, 1986; Arita and Fenton, 1997).

Here, we report the results of a specifically designed study that investigated three sources of variability in bat activity data: (i) variability between sites; (ii) horizontal heterogeneity within a given site, and (iii) night-to-night variability. In addition, we compared two different heights of detectors and two different types of vegetation structure.

The study was conducted to inform the development of an appropriate survey protocol for a subsequent regional-scale investigation on the activity patterns of bats in an agricultural region of southeastern Australia. Agricultural landscapes in southeastern Australia are increasingly attracting the interest of bat ecologists (Lumsden et al., 1995, 2002; Law et al., 1999; Lumsden and Bennett, 2005; Law and Chidel, 2006), but to date, there is a limited quantitative basis upon which to base the design of appropriate survey protocols in these landscapes. The approach we used to investigate multiple sources of variability, as well as some of our general conclusions, are likely to also be applicable to other parts of the world.

\section{Materials AND Methods}

\section{Study Area}

Fieldwork was conducted in the Upper Lachlan catchment of New South Wales, Australia. The region is undulating, receives approximately $600-800 \mathrm{~mm}$ of rainfall in a typical, nondrought year, and has a long-term mean daily maximum temperature of approximately $20^{\circ} \mathrm{C}$ (Lachlan CMA, 2006 and references therein). Prior to the 1800 s, the vegetation was dominated by temperate woodland in the valleys (e.g., Eucalyptus blakelyi, E. melliodora) and dry forest on the hilltops (e.g., E. macrorhynca) - mature trees typically reach approximately $20 \mathrm{~m}$ in height. Following clearing for agriculture and livestock grazing, remnant tree cover on agricultural land now is approximately $10-15 \%$ (Gibbons and Boak, 2002). Relatively large patches of native vegetation remain on hilltops, whereas the valley communities have been severely modified. For example, more than half the remnant cover of the valley-associated yellow box (E. melliodora) occurs in patches smaller than 1 ha (Gibbons and Boak, 2002). Scattered 'paddock' trees are a particularly interesting feature of the region. These trees are often old and typically are not regenerating due to grazing pressure (Spooner et al., 2002; Dorrough and Moxham, 2005). However, they fulfill a range of important ecological functions (Manning et al., 2006), including the provision of foraging habitat for bats (Law et al., 2000; Lumsden and Bennett, 2005).

\section{Data Collection}

One rectangular two-hectare site was set up on each of five different farms (typically but not always measuring $100 \mathrm{~m}$ by $200 \mathrm{~m}$ ). Three sites were in woodland patches (site codes: $\mathrm{cp}, \mathrm{mp}, \mathrm{tu})$ and two were in areas of mature scattered trees (site codes: $\mathrm{dp}, \mathrm{ml}$ ). The five sites were surveyed sequentially for bats throughout January and February 2008. Five 'Anabat' bat detectors (plus ZCAIM storage units) were used at each site (www.titley.com.au). Two 'ground detectors' had their microphones directed upwards at a $45^{\circ}$ angle, $1 \mathrm{~m}$ above the ground. Three 'tree detectors' were mounted on platforms attached to the trunks of trees $2 \mathrm{~m}$ above the ground, and were 
also directed upwards at a $45^{\circ}$ angle (Fig. 1). All detectors were housed in weather-proof boxes. Three locations were surveyed within each site, spread out across the site. Adjacent locations were $>50 \mathrm{~m}$ apart. We did not separate detectors by a specific pre-defined distance, because we focused instead on placing detectors so they would face open areas likely to be used by bats. The first and middle location each had both a ground and a tree detector, facing one another at a distance of approximately $20 \mathrm{~m}$, with an open area in between. The third location had a tree detector only, and was also oriented towards an open area (Fig. 1). Detectors were calibrated following the procedures outlined by Larson and Hayes (2000). Data were recorded from sunset to sunrise for nine consecutive nights at each site (note that sites were surveyed consecutively, resulting in a total of 45 nights of surveys).

Weather records from nearby weather stations were obtained to differentiate between 'suitable' and 'unsuitable' nights for analysis. We subjectively defined suitable nights as those where rainfall at nearby weather stations was $<3 \mathrm{~mm}(n=35)$; there were ten unsuitable nights. Excluding nights with rainfall of $<3 \mathrm{~mm}$ appeared to be overly conservative because bats were active during those nights, and because it would have led to the exclusion of eight additional nights. No nights were unseasonally cold $\left(\right.$ median $=15.9^{\circ} \mathrm{C} ; \min =10.4^{\circ} \mathrm{C}$ ), and high wind speeds were not recorded at night time. We acknowledge that more precise weather data could have been

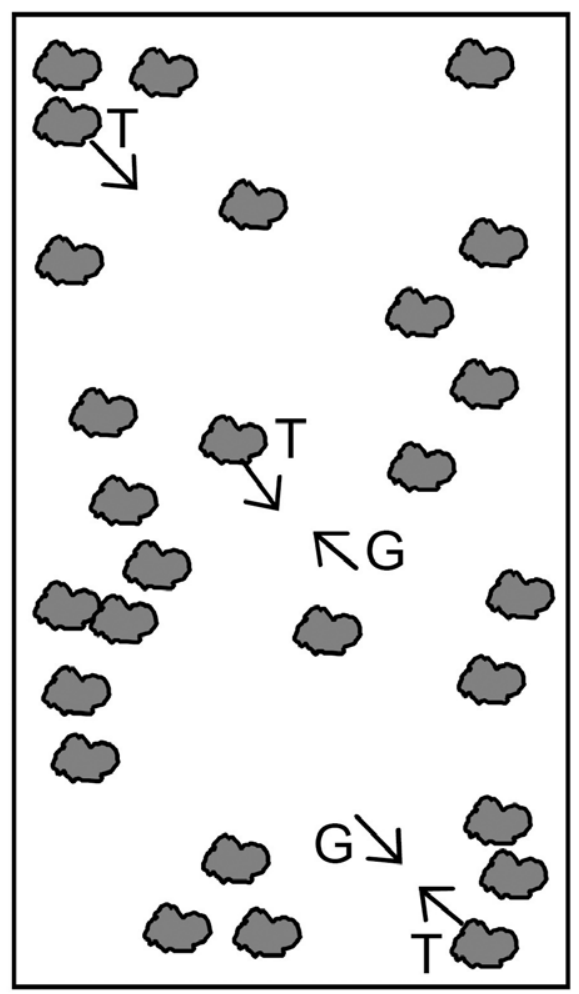

Rectangular 2 ha site

FIG. 1. Schematic map showing the approximate location of detectors within a rectangular 2 ha site, with $\mathrm{T}$ and $\mathrm{G}$ denoting tree and ground detectors, respectively. Grey areas indicate stylised trees, and arrows indicate the direction in which microphones were pointed. The three locations within the site were located at least $50 \mathrm{~m}$ apart obtained if we had used site-level weather stations; and we acknowledge that different definitions of suitable versus unsuitable conditions would have altered some of the details of our findings.

\section{Call Identification}

Bat calls were identified using Anascheme software (Matt Gibson, Ballarat University, unpublished), which is designed to automate the process of call identification. Anascheme reads Anabat files and models individual pulses using regression analysis (Gibson and Lumsden, 2003). Our use of Anascheme incorporated an identification key, which was modified from Law and Chidel (2006) and ground-tested specifically for the study area (BL and MA). As for manual keys (Duffy et al., 2000), automated identification keys work most efficiently when the total number of species considered is kept to a minimum so that overlap in call frequencies is minimized. Our key considered 11 species (following Adams et al., 1988; see Fig. 2). We omitted two eastern species that were unlikely to occur in the study region (Falsistrellus tasmaniensis, Scotorepens orion), although we acknowledge that both of these species may occur in the far eastern, higher altitude parts of the catchment. We also omitted two species that are known from the drier Forbes area to the northwest of the study area (Scotorepens greyii, Chalinolobus picatus). Finally, we omitted the obligate cave-roosting species Miniopterus schreibersii oceanensis. This species is known to roost to the east of the study area at Abercrombie Caves (east of Neville State Forest) and to the north at Borenore Karst Conservation Reserve.

The resulting key used the characteristic frequencies and shapes of different species' ultrasound calls to differentiate between species, and was conservative in its identification to avoid mis-identifications, leading to approximately one third of Anabat files being successfully identified from a given night of remote recordings. Files containing calls from different species were either classified as 'unknown' or, if most calls were attributed to the same species, were identified as passes of the 'dominant' species. More details about the automated identification key are outlined by Law and Chidel (2006), and are available from $\mathrm{BL}$ on request. Using the identification key, we tabulated for each detector and each night the number of passes for each species detected and the total number of identified passes across all species. A pass was defined as a sequence of ultrasonic calls contained within a standard $15 \mathrm{sec}$ file. Files with sizes of $>21$ $\mathrm{kB}$ were excluded prior to analysis because these files were mostly comprised of noise generated by rain or stridulating insects and caused the automated identification software to crash. We acknowledge that other methods exist to quantify bat activity, such as the size of Anabat files (Broders, 2003) or the number of bat calls. Although some alternative measures can be more precise, the number of passes is a well-established and intuitive measure of bat activity, and is appropriate where activity levels of a given species are compared between different locations. Notably, we did not compare activity levels between species.

\section{Data Analysis}

Prior to all analyses, the number of passes identified for a given species per night per detector, and the total number of identified passes per night per detector were log-transformed, because their distributions were highly skewed. There 
were three parts to our analysis: (i) quantitative analysis using mixed regression models; (ii) graphical analysis of individual species; and (iii) graphical analysis of community composition.

\section{Mixed Regression Models}

Our design allowed us to differentiate between three levels of variability in calling activity: between sites, between locations within a site, and between individual nights. In addition, we were able to compare tree detectors with ground detectors (detector type), and woodland sites with scattered tree sites (site type). Given this design, mixed models were appropriate to investigate sources of variability. Mixed models differentiate between random effects and fixed effects, and can be used to account for non-independence of experimental units (Pinheiro and Bates, 2000). Here, nested random effects were specified as 'night', nested within 'location', nested within 'site' (in statistical notation: site/location/night). Detector type and site type were treated as fixed effects. Using this specification, we analysed the log-transformed number of passes by a given species recorded by a given detector in a given night as a function of site type, detector type and their interaction; given the random effects of site/location/night. We used the resulting models to (i) determine the significance of the fixed effects; and (ii) calculate the components of variance accounted for by the random effects. A unique 'component of variance' is associated with each stratum in the experimental design. We summed the components of variance across all strata, and expressed each individual component as a proportion of the sum of individual components. We interpreted this figure as the approximate proportion of variability in calling activity explained at each of four levels of variation - the site level, the location level, the night level, and unexplained residual variation not related to the nesting of experimental units.

\section{Graphical Analysis of Individual Species}

Mixed regression models provided a formal assessment of the relative contributions of different sources of variability. However, they did not provide direct guidance on how many detectors should be used, or for how many nights. For this reason, we also conducted a detailed graphical analysis to complement the formal calculation of components of variance. We reasoned that, in practice, recordings from multiple detectors or nights would be used by bat researchers to calculate the typical, or mean, number of passes per night by a given bat species at a given site. Given our experimental design, there

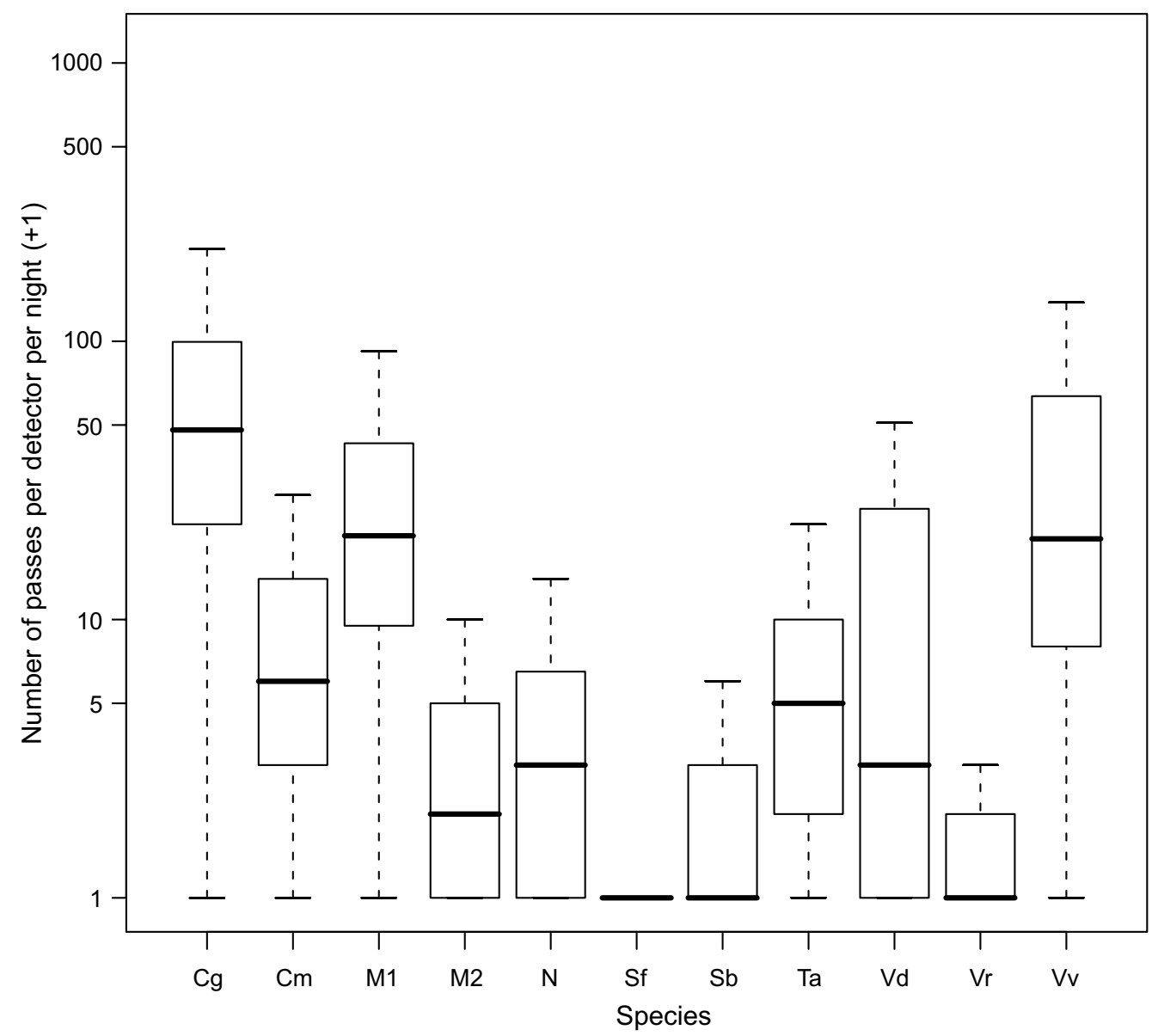

FIG. 2. Distribution of the number of passes recorded by a single detector in a single night, for 11 species or species groups, across all sites and survey nights. $\mathrm{Cg}$ - Chalinolobus gouldii; $\mathrm{Cm}-$ C. morio; $\mathrm{Ml}$ - Mormopterus sp.4 (long-penis form); M2 - Mormopterus sp.2; N - Nyctophilus spp.; Sf - Saccolaimus flaviventris; Sb - Scotorepens balstoni; Ta - Tadarida australis; $\mathrm{Vd}$ - Vespadelus darlingtoni; $\mathrm{Vr}-$ V. regulus; $\mathrm{Vv}-$ V. vulturnus 
were many ways in which such means of 'typical activity' could be calculated. For each species at each site, we calculated the mean level of activity from all possible combinations of detectors for up to nine consecutive nights, starting in all cases with the first night. We did not randomly re-sample nights because we were primarily interested in the actual order of nights observed. We acknowledge that re-sampling would have been feasible, and has been successfully used in other studies (Hayes, 1997).

Some examples illustrate how we calculated mean levels of activity at each site. Let A, B, C, D, E denote the five detectors at a site, and $1,2, \ldots, 9$ denote the number of consecutive nights. Using one detector for one night would yield a single estimate of calling activity - e.g. A-1 would denote the estimate from the first night of sampling by detector A. Calculating the means from two detectors for two nights would yield 10 different plausible estimates: $\mathrm{AB}-2, \mathrm{AC}-2, \mathrm{AD}-2, \mathrm{AE}-2, \mathrm{BC}-2, \mathrm{BD}-2$, BE-2, CD-2, CE-2, and DE-2. Following this logic, we calculated the means from all possible combinations of detectors (between one and five), and all sequences of consecutive nights (from 1 to 9 , always starting with 1). The resulting means were then graphed as a function of the number of detectors used ( 1 to 5 ) and the number of nights of consecutive recordings (1-9). The mean number of passes by all recorders at a given site over all nights was used as a baseline for a 'best estimate' of the level of activity, and running means were compared graphically against this best estimate.

\section{Graphical Analysis of Community Composition}

Many habitat studies are aimed not only at a single species, but also the overall community composition at different sites. To address this issue, we used a combination of multivariate distance estimation and multi-dimensional scaling (Clarke and Warwick, 1994) to visualise if different estimates of community composition from a given site were increasingly tightly clustered when estimates were based on more nights or detectors. Specifically, we constructed a matrix of all species by all detector-night combinations (e.g., AB-2, AB-3, etc.; see above), with each cell containing the mean (log-transformed) number of passes by a given species. We then calculated the Bray-Curtis distance between different detector-night combinations, both within and between sites. Non-metric multi-dimensional scaling was used to visualise these distances in a two-dimensional plot (Clarke and Warwick, 1994).

\section{Equipment Failure and Weather}

At two sites, one of the detectors failed, meaning we effectively had only four detectors. All analyses were conducted twice - once including all nine consecutive nights, and once including only 'suitable nights' (see 'Data Collection' above).

\section{RESULTS}

Eleven species or species groups were identified. The number of passes recorded by these species in a given night varied greatly, encompassing a range from 0 to over 1,000, with medians between 0 and 50 for the different species (Fig. 2).

\section{Mixed Regression Models}

Mixed regression models were constructed for the five most frequently recorded species (Fig. 3). Using only suitable nights, broadly similar patterns in variability were observed for Chalinolobus gouldii, Vespadelus vulturnus, Mormopterus sp.4, and Chalinolobus morio. Generalising across these species, typically, over $40 \%$ of the overall variance occurred at the between-site level; approximately

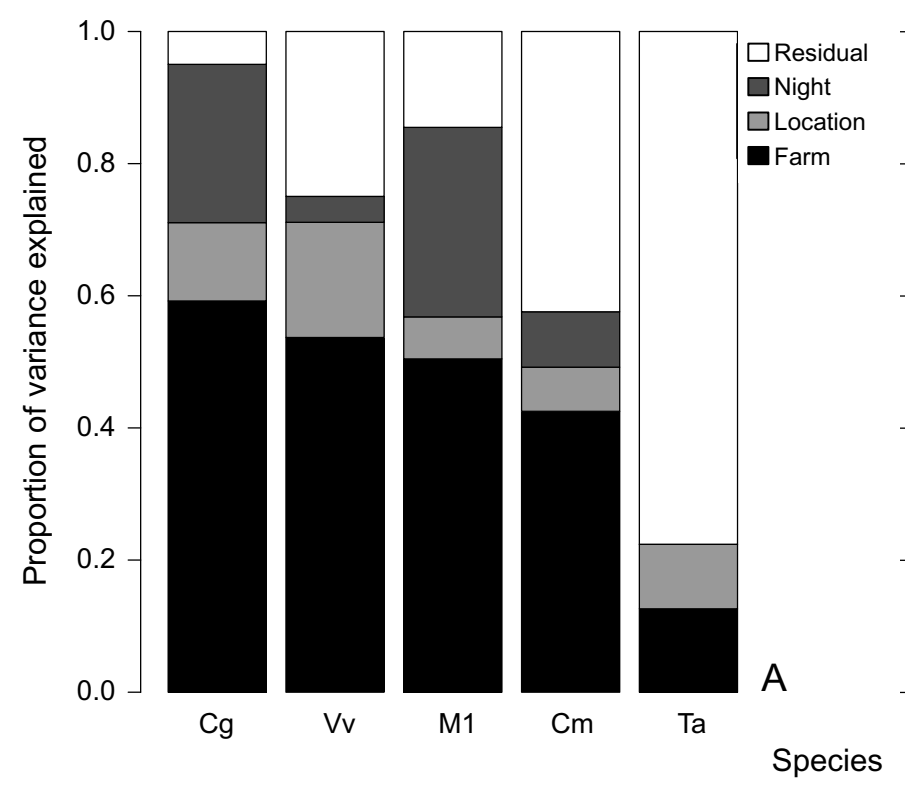

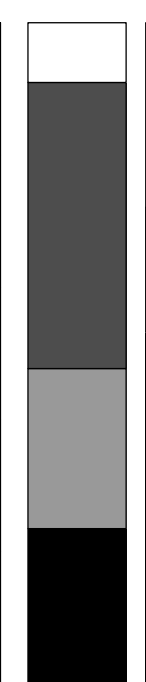

$\mathrm{Cg}$

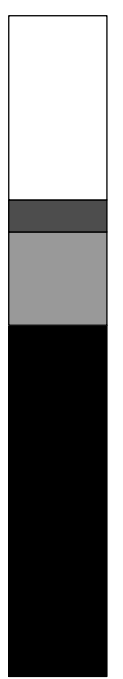

$\mathrm{V} v$

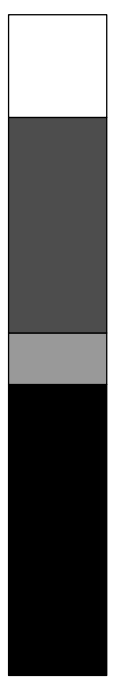

M1

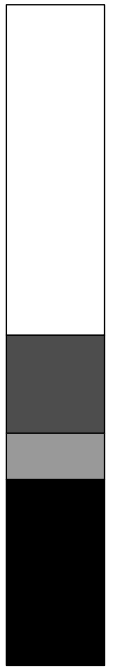

$\mathrm{Cm}$

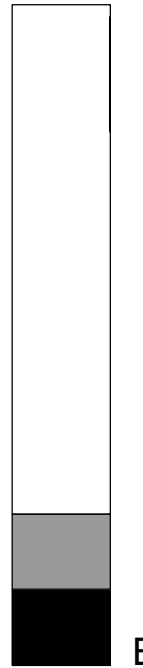

$\mathrm{Ta}$

FIG. 3. Components of variance at four levels of the experimental design for the five most frequently recorded species. A: Based on 'suitable' nights only. B: Based on all nights regardless of weather. See Fig. 1 for species abbreviations 
$10 \%$ occurred between the three locations where detectors were located; approximately $20 \%$ was explained by night-to-night differences; and the remainder was additional variability not attributable to systematic variation within experimental units. Tadarida australis was also analysed individually, but residual variability was extremely high for this species $(\approx 80 \%$; Fig. $3 \mathrm{~A})$.

With respect to the fixed effects, separate regression models for four species showed that tree detectors recorded a significantly higher number of passes than ground detectors $(P<0.05$; Table 1$)$. For $V$. vulturnus, this relationship was more complex. A significant interaction between site type and detector type suggested that the tree detectors recorded more passes than ground detectors in scattered tree sites, but not in woodland sites (Table 1).

We repeated the regression analyses using data from all nights, including 'unsuitable' ones where precipitation was recorded. The qualitative conclusions regarding the fixed effects were similar, with tree detectors recording more passes (not shown). However, the relative contributions of different components of variance shifted substantially when all nights were included - in particular, previously identified patterns in between-site variability were masked by higher between-night variability and higher unexplained residual variability (Fig. 3B).

\section{Graphical Analysis of Individual Species and Community Composition}

At all sites, for the five most active species, the mean number of passes calculated from several detectors over a series of nights stabilised and reached an asymptote with increases in the number of nights and number of detectors used. For example, the mean activity level of $C$. morio stabilised at farm 'tu' (Fig. 4), and similar patterns were found for other species at other sites (not shown).

The calculation of Bray-Curtis distances of bat community composition within and between sites provided insights on how the estimates of overall bat community composition changed with increasing survey effort. Multi-dimensional scaling showed that between-site differences could be masked by within-site variability resulting from a lack of survey effort. Sites began to separate in multidimensional scaling plots if two or more detectors were used for two suitable nights; clear separation was achieved after at least four suitable nights (Fig. 5).

\section{DisCUSSION}

There is no simple recipe for what constitutes an ideal survey effort, because additional effort will always result in more precise estimates of activity. Hence, a more useful question is what constitutes a reasonable survey effort given the objectives of a particular study. In the case of habitat studies, objectives typically are to differentiate between (1) highly suitable and less suitable sites for a given species, and (2) the communities of species using different areas. These objectives suggest that a useful way to tackle the problem of how much survey effort should be used is to differentiate between within-site variability and between-site variability.

TABLE 1. Significant fixed effects in the regression models for the (log-transformed) number of passes recorded by one detector in a night for five individual bat species. The total degrees of freedom were 160 in each model, with the intercept and every significant predictor using one degree of freedom each

\begin{tabular}{llccc}
\hline \multicolumn{1}{c}{ Response variable } & \multicolumn{1}{c}{ Explanatory variable } & $\begin{array}{c}\text { Parameter } \\
\text { estimate }\end{array}$ & $\begin{array}{c}\text { Standard } \\
\text { error }\end{array}$ & $P$-value \\
\hline Chalinolobus gouldii & Intercept & 3.600 & 0.510 & $<0.001$ \\
& Detector position (tree) & 0.158 & 0.060 & $<0.05$ \\
C. morio & Intercept & 1.370 & 0.363 & $<0.001$ \\
& Detector position (tree) & 0.688 & 0.136 & $<0.001$ \\
Mormopterus sp.4 (long-penis form) & Intercept & 2.730 & 0.433 & $<0.001$ \\
& Detector position (tree) & 0.275 & 0.093 & $<0.01$ \\
Tadarida australis & Intercept & 1.280 & 0.261 & $<0.001$ \\
\multirow{4}{*}{ Vespadelus vulturnus } & Detector position (tree) & 0.481 & 0.186 & $<0.05$ \\
& Intercept & 1.180 & 1.010 & 0.25 \\
& Detector position (tree) & 1.110 & 0.261 & $<0.001$ \\
& Site type (woodland) & 2.380 & 1.310 & 0.17 \\
& Det. position (tree) $\times$ Site type (woodland) & -1.160 & 0.342 & $<0.01$ \\
\hline
\end{tabular}



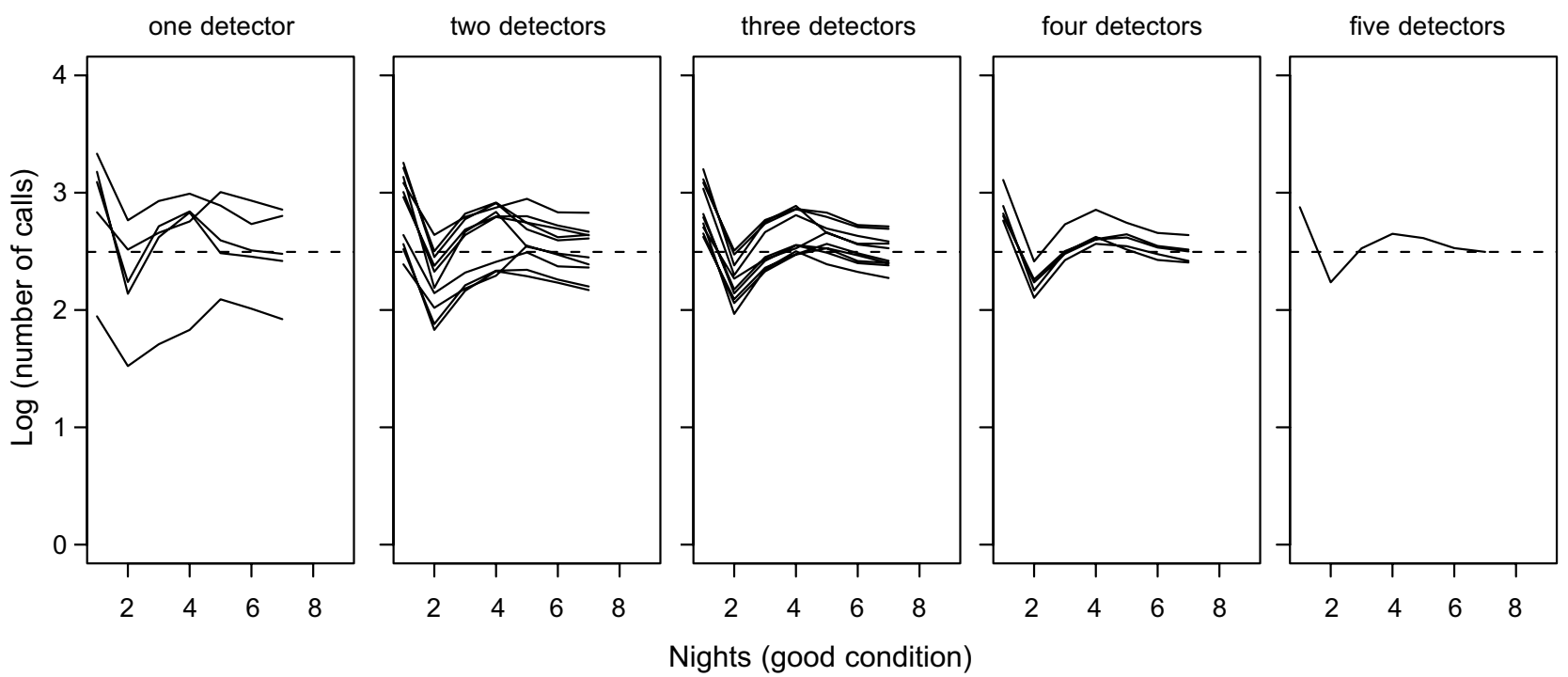

FIG. 4. Mean levels of activity of $C$. morio calculated using combinations of different detectors, over a series of consecutive nights with suitable conditions at one selected farm ('tu'). The dotted line indicates the overall 'grand mean' level of activity calculated across the maximum number of nights and detectors available. As the number of nights and detectors increased, the estimate of activity became increasingly precise

\section{Mixed Regression Models}

For four out of five species examined, most variability occurred at the between-site level (Fig. 3A). That is, for our particular set of sites and species, estimates of bat activity from a single detector recording for a single night were likely to be sufficient to pick up some differences in activity between sites. This lends support to the viability, where necessary, of conducting rapid surveys where single detectors are moved to a new site every night. Rapid surveys with little replication at the within-site level are often unavoidable when the number of sites is large (Law and Chidel, 2006). If rapid surveys are the only feasible survey method, and are used as the basis for habitat analyses, the ability to differentiate between activity levels at different sites is greatly enhanced if surveys are only conducted on 'suitable' nights, or if 'unsuitable' nights are excluded from later analyses (Fig. 3). This is because including 'unsuitable' nights can introduce substantial additional night-to-night variability thereby masking actual site-to-site differences (Fig. 3). In addition to rainfall, 'unsuitable' nights could include those with low temperatures (Richards, 1989) or strong winds (Adam et al., 1994; Verboom and Spoelstra, 1999). Ideally, rapid surveys should record data from all treatments simultaneously each night, and resulting habitat models should include temperature and other weather variables as covariates.
For at least four out of five species, we found that tree detectors detected significantly more passes than ground detectors (Table 1). However, the ecological significance of this difference may be minimal. Parameter estimates for tree detectors (as opposed to ground detectors) ranged between approximately 0.2 and 0.7 . Because the response variable was on the log-scale, this suggests that the difference in passes recorded per night between the detector types is between $\mathrm{e}^{0.2} \approx 1.2$ and $\mathrm{e}^{0.7} \approx 2.0$. That is, an additional one or two passes per species were recorded by tree detectors in a given night, compared with ground detectors. Especially for common species, this difference will often be negligible given typical activity levels in a night (Fig. 2).

Despite the small difference in the number of passes recorded at different heights, we suggest that tree detectors are likely to be preferable to ground detectors for acoustic monitoring in locations with a more open vegetation structure. Though our data were insufficient for formal analysis, previous work suggested that detectors at a greater height can increase the probability of detecting bats flying around the crowns of paddock trees, particularly species with low intensity calls (e.g., Nyctophilus spp. Adams, 2000). Additionally, in agricultural landscapes, an important practical consideration is that tree detectors are more secure from livestock than ground detectors. Our tree and ground detectors were only separated by $1 \mathrm{~m}$ in height and, relative to tree height, were situated close to the ground. 

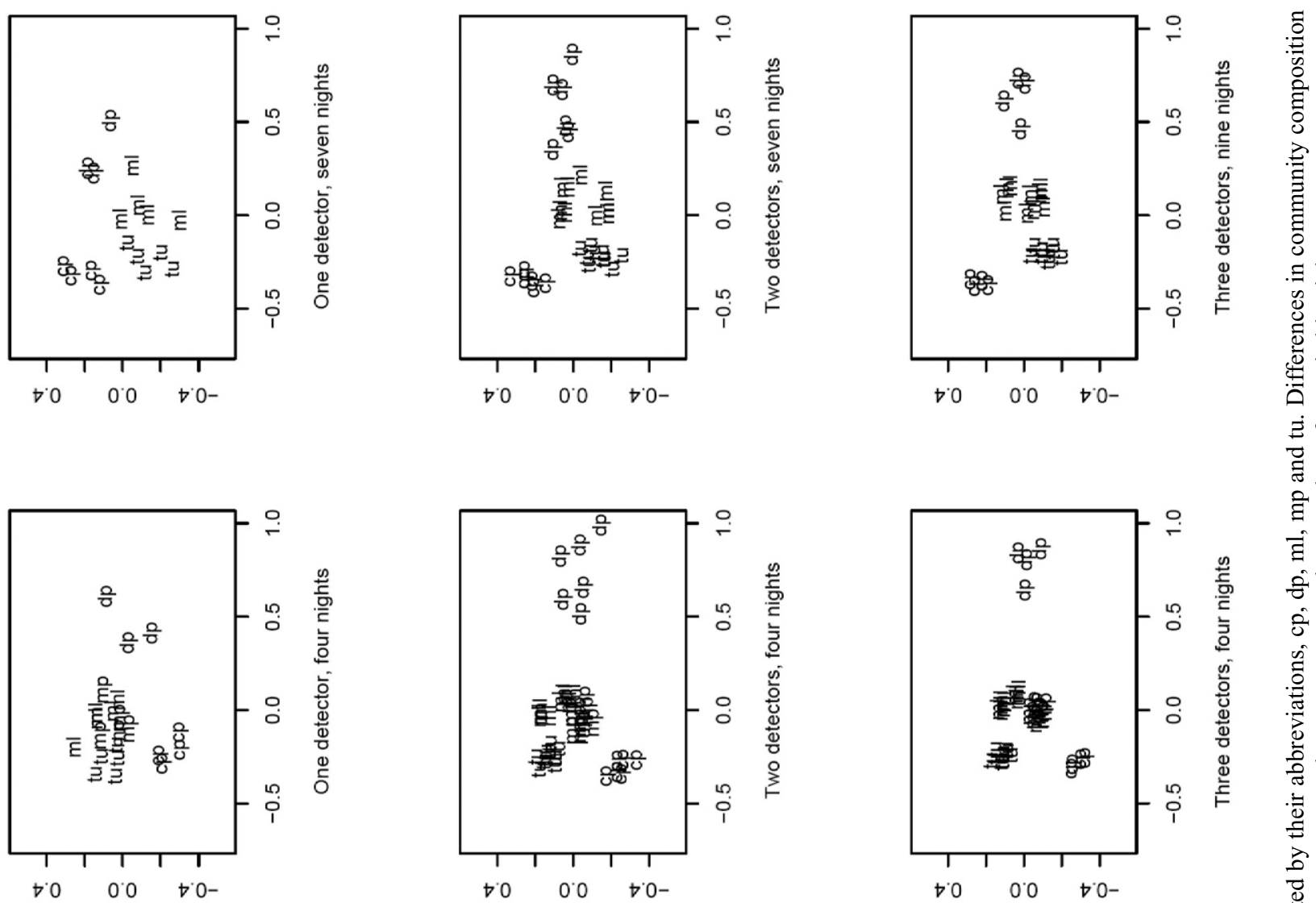

몷
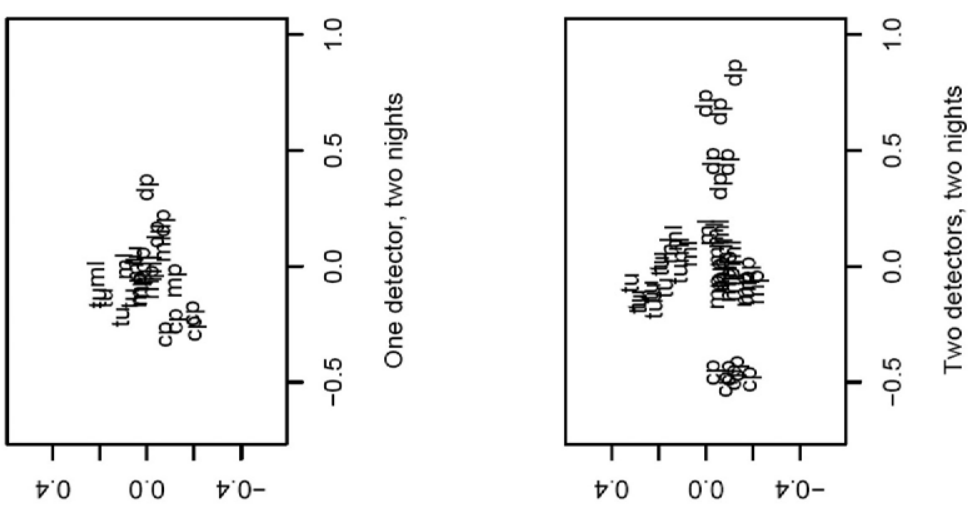

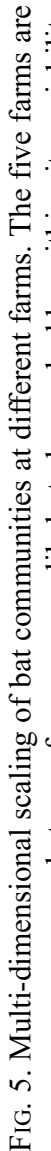
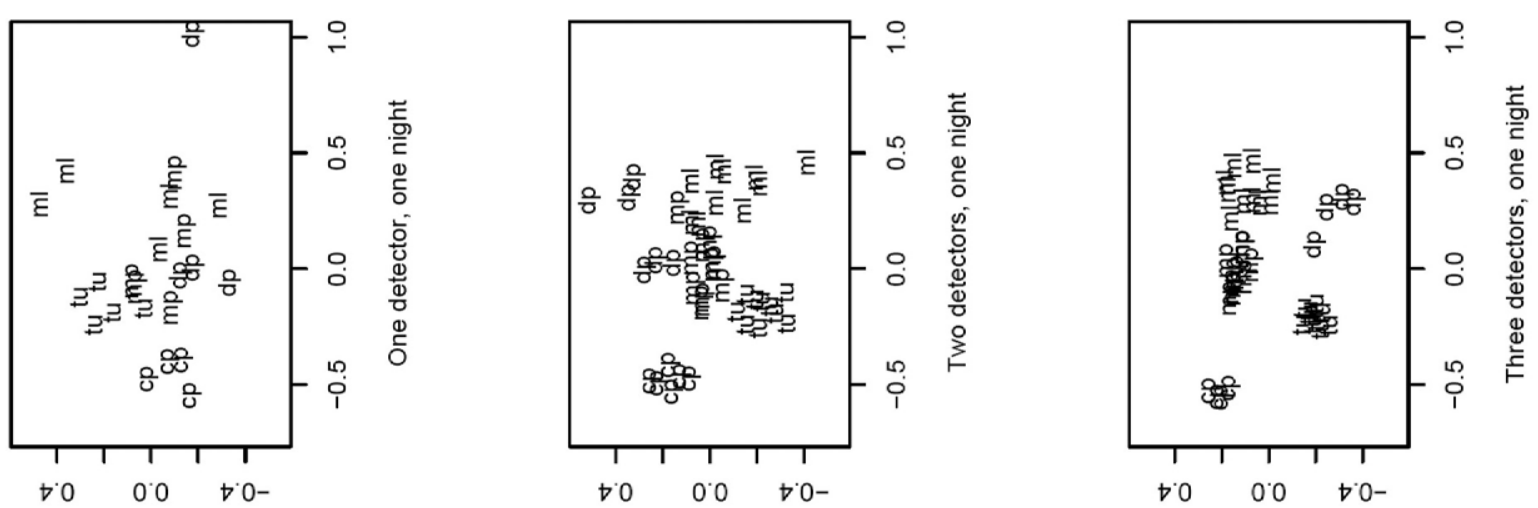
Despite this, we identified all of the 11 species or species groups included in our automated key. This suggests that call detectability was not restricted at these heights, perhaps due to the lack of a complex understorey. The need to place detectors at greater heights than those used in our study is likely to be more relevant in landscapes with taller or more densely spaced trees, and a greater extent of vertical stratification.

Apart from one significant interaction, which was difficult to interpret and may be an artifact of the particular sites surveyed in this study, we found no significant differences in the activity of individual bat species between scattered tree sites and woodland sites (Table 1). This result supports the notion that many bats in southeastern Australia use both woodland sites and scattered tree sites (Law et al., 2000; Lumsden et al., 2002; Lumsden and Bennett, 2005). However, the consistent lack of any significant differences between woodland sites and scattered tree sites in our study is likely to be attributable primarily to low statistical power. 'Site type' was a treatment at the highest level of the experimental design, and had very low levels of replication.

\section{Graphical Analyses}

The graphical analyses were useful to visualize how increases in the number of detectors and number of nights resulted in more precise estimates of activity levels, both for individual species (Fig. 4) and for estimates of community composition (Fig. 5). There were systematic differences between the three locations within a site (Fig. 3), and differences between detectors (Fig. 4). These differences highlight the importance of careful calibration (Larson and Hayes, 2000), and strongly suggest that using multiple detectors can be worthwhile (Duchamp et al., 2006) (Figs. 4 and 5). This result is interesting because (i) most discussions on within-site variability have focused on the need to survey for multiple nights (e.g. Hayes, 1997; Moreno and Halffter, 2000) rather than considering other sources of within-site variability (but see Hayes, 2000; Hayes and Gruver, 2000; Lumsden and Bennett, 2005); and (ii) financial constraints can make it difficult to use multiple detectors per site.

Where only one detector per site can be used due to financial constraints, the approach by Lumsden and Bennett (2005) may be a useful compromise. They used a single detector but moved it to a different location within the site every night.
Although we did not test their method explicitly, this approach is likely to be useful in accounting for spatial heterogeneity in activity levels within a site. Where multiple detectors can be used, it should be noted that the gain in precision of using an additional detector is particularly pronounced when comparing the use of a single detector versus the use of two detectors (Figs. 4 and 5).

A critical question for habitat studies is whether the estimates of bat activity obtained are precise enough to be able to differentiate between different sites. For community composition, multi-dimensional scaling suggested that, in this study, differentiation between sites was achieved when two or more detectors were used for two nights, but differentiation became clearer when detectors were used for four or more nights (Fig. 5).

\section{Considerations for the Design of Habitat Studies}

The specific results of our work may not translate directly to other regions. However, we suggest six general considerations that can help with the design of effective habitat studies using bat detectors.

(i) Consider the key contrasts of interest in the study. If subtle differences between sites are of interest, survey effort needs to be substantially greater than if coarse differences are of interest. Coarse differences, e.g. between different land use types, can sometimes be detected with as little as a single detector operating for a single night;

(ii) Use data from suitable nights only. Data from poor nights can introduce additional variability, resulting in a lack of precision in estimates of bat activity despite higher survey effort. This means, for example, that it may be more useful to consider the mean level of activity from five suitable nights rather than from nine nights that had a mix of suitable and unsuitable conditions;

(iii) Calibrate detectors. To differentiate between genuine within-site differences in bat activity, and differences in the sensitivity of multiple detectors, it is important that detectors are carefully calibrated (Larson and Hayes, 2000). Undesirable effects arising from variability in detector sensitivity can be further minimized by rotating detectors among different treatments throughout the course of a study;

(iv) Survey for multiple nights. Night-to-night variability typically accounted for $20 \%$ of the overall variability in activity levels. This suggests that surveying for multiple nights is particularly important to reduce unwanted within-site variability. More 
nights will always result in more precise estimates of activity. In this study, reasonable levels of precision were achieved after four suitable nights, especially if multiple detectors were used;

(v) Account for spatial heterogeneity in activity levels within a site. Though less important than nightto-night variability, spatial heterogeneity within a site typically accounted for approximately $10 \%$ of the overall variability in activity levels. In practice, financial constraints are considerable, suggesting two practical solutions to account for spatial withinsite variability: (a) use two (or more) detectors, or (b) move a single detector between several locations within a site;

(vi) Consider whether vertical differentiation in habitat use is likely. In this study, tree detectors recorded slightly more passes for all species examined. However, in the woodland environment we examined (with mature trees typically reaching only $\approx 20 \mathrm{~m}$ in height), we did not expect strong vertical heterogeneity in bat activity. Where vertical vegetation structure is more pronounced, using several different detector heights is likely to be more important. In farming landscapes, tree detectors may be an effective means of protecting survey equipment from livestock.

These considerations are general. As in all ecological field studies, ecological, statistical, logistical and financial considerations need to be balanced. Structured pilot studies like ours can be useful to explicitly weigh up multiple considerations.

\section{ACKNOWLEDGEMENTS}

Thanks to G. King, G. and L. Molloy, V. Heffernan, J. Walsh and G. Johnson for allowing us to survey bats on their properties. Thanks also to K. Newport for his assistance with harp trapping for the development of the local identification key. We are particularly grateful to Matt Gibson for generously providing the Anascheme software, without which our analyses would not have been possible. We greatly appreciate funding by the Australian Research Council and the ANU College of Science. Comment by two anonymous referees helped to improve an earlier draft of this manuscript.

\section{Literature Cited}

AdAM, M. D., M. J. LACKI, and L. G. Shoemaker. 1994. Influence of environmental conditions on flight activity of Plecotus townsendii virginianus (Chiroptera: Vespertilionidae). Brimleyana, 21: 77-85.

ADAMs, M. D. 2000. Bat activity around scattered remnant trees in a rural landscape. The Australian Bat Society Newsletter, 14: 7-13.

Adams, M., T. R. Reardon, P. R. Baverstock, and C. H. S. WATTS. 1988. Electrophoretic resolution of species boundaries in Australian Microchiroptera. IV. The Mollossidae (Chiroptera). Australian Journal of Biological Science, $41:$ 315-326.

Arita, H. T., and M. B. Fenton. 1997. Flight and echolocation in the ecology and evolution of bats. Trends in Ecology and Evolution, 12: 53-58.

Austin, M. P. 2002. Spatial prediction of species distribution: an interface between ecological theory and statistical modelling. Ecological Modelling, 157: 101-118.

Broders, H. G. 2003. Another quantitative measure of bat species activity and sampling intensity considerations for the design of ultrasonic monitoring studies. Acta Chiropterologica, 5: 235-241.

Clarke, K. R., and R. M. WARwick. 1994. Change in marine communities: an approach to statistical analysis and interpretation. Plymouth Marine Laboratory, Plymouth, UK, $172 \mathrm{pp}$.

Dorrough, J., and C. Moxham. 2005. Eucalypt establishment in agricultural landscapes and implications for landscapescale restoration. Biological Conservation, 123: 55-66.

Duchamp, J. E., M. Yates, R. M. Muzika, and R. K. Swihart. 2006. Estimating probabilities of detection for bat echolocation calls: an application of the double-observer method. Wildlife Society Bulletin, 34: 408-412.

Duffy, A. M., L. F. Lumsden, C. R. CAdDle, R. R. ChicK, and G. R. Newell. 2000. The efficacy of Anabat ultrasonic detectors and harp traps for surveying microchiropterans in south-eastern Australia. Acta Chiropterologica, 2: 127-144.

Fenton, M. B., and G. P. BeLl. 1981. Recognition of species of insectivorous bats by their echolocation calls. Journal of Mammalogy, 62: 233-243.

GibBOns, P., and M. BOAK. 2002. The value of paddock trees for regional conservation in an agricultural landscape. Ecological Management and Restoration, 3: 205-210.

GiBson, M., and L. LumsDEN. 2003. The Anascheme automated bat call identification system. The Australian Bat Society Newsletter, 20: 24-26.

GRIFFIN, D. R. 1971. The importance of atmospheric attenuation for the echolocation of bats (Chiroptera). Animal Behaviour, 19: 55-61.

Guisan, A., and N. E. ZimmermanN. 2000. Predictive habitat distribution models in ecology. Ecological Modelling, 135: 147-186.

HAYES, J. P. 1997. Temporal variation in activity of bats and the design of echolocation-monitoring studies. Journal of Mammalogy, 78: 514-524.

HAYES, J. P. 2000. Assumptions and practical considerations in the design and interpretation of echolocation-monitoring studies. Acta Chiropterologica, 2: 225-236.

Hayes, J. P., and J. C. GRUVER. 2000. Vertical stratification of bat activity in an old-growth forest in western Washington. Northwest Science, 74: 102-108.

LaChlan CMA. 2006. Lachlan Action Plan. Lachlan Catchment Management Authority, Cowra, New South Wales, 199 pp.

LARSON, D. J., and J. P. HAYES. 2000. Variability in sensitivity of Anabat II bat detectors and a method of calibration. Acta Chiropterologica, 2: 209-213.

LAW, B. S. 2004. Challenges for managing bats in the State forests of New South Wales. Pp. 748-760, in Conservation of Australia's forest fauna, 2nd edition (D. LuNNEY, ed.). Royal Zoological Society of New South Wales, Mosman, $1073 \mathrm{pp}$.

LAW, B. S., and M. CHIDEL. 2006. Eucalypt plantings on farms: 
Use by insectivorous bats in south-eastern Australia. Biological Conservation, 133: 236-249.

LaW, B., J. Anderson, and M. Chidel. 1998. A bat survey in State Forests on the south-west slopes region of New South Wales with suggestions for improvements in future surveys. Australian Zoologist, 30: 467-479.

LaW, B. S., J. Anderson, and M. Chidel. 1999. Bat communities in a fragmented forest landscape on the south-west slopes of New South Wales, Australia. Biological Conservation, 88: 333-345.

LAw, B. S., M. Chidel, and G. Turner. 2000. The use by wildlife of paddock trees in farmland. Pacific Conservation Biology, 6: 130-143.

Lumsden, L. F., and A. F. Bennett. 2005. Scattered trees in rural landscapes: foraging habitat for insectivorous bats in south-eastern Australia. Biological Conservation, 122: 205-222.

Lumsden, L. F., A. F. Bennett, S. P. Krasna, and J. E. Silins. 1995. The conservation of insectivorous bats in rural landscapes of northern Victoria. People and Nature Conservation: $142-148$.

Lumsden, L. F., A. F. BennetT, and J. E. Silins. 2002. Location of roosts of the lesser long-eared bat Nyctophilus geoffroyi and Gould's wattled bat Chalinolobus gouldii in a fragmented landscape in south-eastern Australia. Biological Conservation, 106: 237-249.

Manning, A. D., J. Fischer, and D. B. Lindenmayer. 2006. Scattered trees are keystone structures - implications for conservation. Biological Conservation, 132: 311-321.

Menzel, J. M., M. A. Menzel, J. C. Kilgo, W. M. Ford, J. W. EdWARDS, and G. F. MCCRACKEN. 2005. Effect of habitat and foraging height on bat activity in the coastal plain of South Carolina. Journal of Wildlife Management, 69: 235-245.

Milne, D. J., M. Armstrong, A. Fisher, T. Flores, and C. R. PAVEY. 2004. A comparison of three survey methods for collecting bat echolocation calls and species-accumulation rates from nightly Anabat recordings. Wildlife Research, 31: $57-63$.

Milne, D. J., A. Fisher, I. Rainey, and C. R. Pavey. 2005. Temporal patterns of bats in the top end of the Northern Territory, Australia. Journal of Mammalogy, 86: 909-920.

Moreno, C. E., and G. Halffter. 2000. Assessing the completeness of bat biodiversity inventories using species accumulation curves. Journal of Applied Ecology, 37: 149-158.

O'FARrell, M. J., and W. L. GANNON. 1999. A comparison of acoustic versus capture techniques for the inventory of bats. Journal of Mammalogy, 80: 24-30.

O'Neill, M. G., and R. J. TAYlor. 1986. Observations on the flight patterns and foraging behavior of Tasmanian bats. Australian Wildlife Research, 13: 427-432.

Patriquin, K. J., L. K. Hogberg, B. J. Chruszcz, and R. M. R. BARCLAY. 2003. The influence of habitat structure on the ability to detect ultrasound using bat detectors. Wildlife Society Bulletin, 31: 475-481.

Pinheiro, J. C., and D. M. Bates. 2000. Mixed-effects models in S and S-Plus. Springer-Verlag, New York, 528 pp.

RichARDS, G. C. 1989. Nocturnal activity of insectivorous bats relative to temperature and prey availability in tropical Queensland. Australian Wildlife Research, 16: 151-158.

SpoOner, P., I. Lunt, and W. Robinson. 2002. Is fencing enough? The short-term effects of stock exclusion in remnant grassy woodlands in southern NSW. Ecological Management and Restoration, 3: 117-126.

Verboom, B., and K. Spoelstra. 1999. Effects of food abundance and wind on the use of tree lines by an insectivorous bat, Pipistrellus pipistrellus. Canadian Journal of Zoology, 77: 1393-1401.

Waters, T. J., and A. L. WAlsh. 2002. The influence of bat detector brand on the quantitative estimation of bat activity. Bioacoustics, 5: 205-221.

Weller, T. J., and C. J. ZABeL. 2002. Variation in bat detections due to detector orientation in a forest. Wildlife Society Bulletin, 30: 922-930.

Received 22 January 2009, accepted 07 March 2009 
